\title{
The psychological burden in survivors of stroke and caregivers dyads in Kinshasa (Democratic Republic of Congo): a cross-sectional study
}

\section{Germain Manzekele Bin Kitoko ( $\square$ gbinkitoko@gmail.com )}

Department of Psychiatry, University of Kinshasa, Lemba, Kinshasa, Democratic Republic of Congo. Bives Mutume. Vivalya

Department of Psychiatry and Mental Health, Kampala International University Western Campus, Ishaka, Uganda.

\section{Martial Mumbere Vagheni}

Department of Psychiatry, University of Kinshasa, Lemba, Kinshasa, Democratic Republic of Congo.

\section{Thierry Matonda Ma Nzuzi}

Department of Psychiatry, University of Kinshasa, Lemba, Kinshasa, Democratic Republic of Congo.

\section{Sam Mampunza Lusambulu}

Department of Psychiatry, University of Kinshasa, Lemba, Kinshasa, Democratic Republic of Congo.

\section{Gilbert Mananga Lelo}

Department of Psychiatry, University of Kinshasa, Lemba, Kinshasa, Democratic Republic of Congo.

\section{Magloire Nkosi Mpembi}

Department of Psychiatry, University of Kinshasa, Lemba, Kinshasa, Democratic Republic of Congo.

\section{Samuel Mampunza Ma Miezi}

Department of Psychiatry, University of Kinshasa, Lemba, Kinshasa, Democratic Republic of Congo.

\section{Research Article}

Keywords: Psychological burden, Anxiety, Depression, Kinshasa, Stroke survivors, caregivers

Posted Date: March 22nd, 2021

DOl: https://doi.org/10.21203/rs.3.rs-336489/v1

License: (c) (i) This work is licensed under a Creative Commons Attribution 4.0 International License. Read Full License 
The psychological burden in survivors of stroke and caregivers dyads in Kinshasa (Democratic Republic of Congo): a cross-sectional study

Germain Manzekele Bin Kitoko ${ }^{1 *}$ Bives Mutume Vivalya ${ }^{2}$ Martial Mumbere Vagheni ${ }^{1}$ Thierry Matonda Ma Nzuzi ${ }^{1}$ Sam Mampunza Lusambulu ${ }^{1}$ Gilbert Mananga Lelo ${ }^{1}$ Magloire Nkosi Mpembi ${ }^{1}$ Samuel Mampunza Ma Miezi ${ }^{1}$

${ }^{1}$ Department of Psychiatry; University of Kinshasa, Lemba, Kinshasa, Democratic Republic of Congo.

${ }^{2}$ Department of Psychiatry and Mental Health, Kampala International University Western Campus, Ishaka, Uganda.

Corresponding author:

Dr. Germain Manzekele Bin Kitoko Department of Psychiatry, University of Kinshasa, Lemba, Kinshasa, Democratic Republic of Congo Email: gbinkitoko@gmail.com 


\section{Abstract}

Background: Stroke exposes the patients and the caregivers to the development of burden in terms of health, economic and social costs. Few studies have focused on the relationship between the psychological burden and the level of disability in stroke survivors and caregiver dyads.

Methods: This cross-sectional study aimed at determining the psychological burden of stroke in patients and caregivers in Kinshasa. 85 stroke survivors and caregivers dyads were screened using the Hospital Anxiety and Depression Scale, the Zarit Burden Inventory, and the Rankin's modified Scale to determine respectively the depression, the anxiety in stroke survivors as well as the caregivers' psychological burden.

Results: Up to fifty percent of survivors of stroke had a severe disability, associated with a high risk of the occurrence of the psychological burden. Nearly eighty-five percent of caregivers showed a moderate psychological burden. The stroke survivors developed more depression than anxiety. Caregivers developed more likely anxiety and depression than stroke survivors.

Conclusions: There is a positive relationship between the psychological burden in caregivers and the level of disability in stroke survivors far from the acute phase of the stroke. Healthcare providers working with the survivors of stroke should assess for anxiety and depression in caregivers.

Keywords: Psychological burden, Anxiety, Depression, Kinshasa, Stroke survivors, caregivers. 


\section{Background}

Stroke exposes the patients and the caregivers to the development of burden in terms of health, economic, and social costs. Early management helps to reduce the morbidity and mortality related to the stroke which is the first cause of acquired disability among adult individuals over the world [1]. Research on the outcomes showed that survivors of strokes experience the impairment of their daily functioning [2]. A rate of $75 \%$ of permanent disability in stroke survivors has been reported $[1-3]$.

Numerous studies showed the increased rate of depression and anxiety in both the stroke survivors and their caregivers within the two years of the stroke $[1,4,5]$. In addition, the socioeconomic status prior to the stroke correlated with the early occurrence of psychological burden in the survivors of stroke as well as the level of disability [2-7]. Caregivers of the survivors of stroke often experience psychological disturbances which impaired continuous management, rehabilitation, social reinsertion as well as outcomes $[4,5]$.

The cognitive, emotional, and physiological reactions of caregivers are the core elements of early recovery in stroke survivors [6]. A recent study revealed that the poor caregiver's psychological health is characterized by alteration of social support, poor adherence to treatment, and financial disruption of the stroke survivors [7-9]. Anxiety occurred more likely in caregivers of stroke survivors than depression $[10,11]$. Additionally, the presence of psychological burden in caregivers increased the risk of the early death of stroke survivors [12-14].

In developing countries, few studies have focused on the relationship between the symptoms of depression and anxiety among caregivers and the level of disability in stroke survivors. However, the greater score of the Hospital Anxiety and Depression Scales (HADS) [15] was associated with a high level of disability in stroke survivors, associated with the increased vulnerability in caregivers [16]. The aim of this study was to assess the psychological burden in stroke survivors and caregivers dyads as well as to determine its relationship with the level of disability in the survivors of stroke.

\section{Methods}

\section{Participant's recruitment}

To carry out this cross-sectional study, 85 stroke survivors and caregivers dyads aged above 18 years who attained the rehabilitation center of Kinshasa (DRC) from December 1, 2014, to January 
31, 2015, and had a stable mental state with full cognitive functioning, and without a history of mental disorders were recruited for this study. Exclusions were survivors of stroke and caregivers dyads with a history of substance abuse and mental disorders, those who had an acute mental disorder or medical illness; or the caregivers who were not living the patients within the two months last to the collection data session. Participants provided informed consent after being explained the objectives of the study. The study was approved by the Ethics Committee of the Public Health School of the University of Kinshasa and conducted according to the Declaration of Helsinki.

\section{Gold standard testing}

A semi-structured questionnaire established from the Zarit Burden Inventory (ZBI) [17] and the HADS [18] translated in French and from the demographic information was used to collect data. Moreover, the caregivers responded to questions related to whether they were trained, assisted by their family, and the kind of relationship with the patients; a history of taking care of a survivor of the stroke.

\section{Measurement}

Two trained research assistants supervised by the first author collected data. The study was based on convenience sampling. The questionnaire was presented and explained to the potential participants who were requested to answer and handle it after the fulfillment. The semi-structured questionnaire took about 25 minutes to complete

To determine the psychopathological profile of study participants, the stroke survivors and caregivers were assessed using: i) the ZBI, which is a validated decoding tool initially used to assess the burden of caregivers close to dementia patients and many chronic disorders [19] and for which the participant was asked to respond to 22 items established from a questionnaire, with a variable score from 0 (None), 1 (rarely), 2 (sometimes), 3 (usually), 4 (anytime). Commonly, the ZBI score is classified in three ranges: mild (21-40), moderate (41-60), and severe (up to 60); ii) the Rankin's modified score (mRS) tool measured the functional independence and scored between 0 and 6 points: 0 (no symptoms of disability), 1 (no major handicap), 2 (mild inability), 3 (moderate disability), 4 (moderate disability), 5 (severe invalidity) and 6 (death of the patient). In this study, the score above 2 indicated a severe handicap, versus a score less than or equal to 2 for a not serious handicap; iii) the HADS, developed by Zigmond and Snaith [18] is a self-report questionnaire usually used to assess the level of anxiety and depression; translated into many languages and have an optimal cut-off $\geq 8$ (sensitivity 0.89 , specificity 0.75 ), to generalized anxiety disorders. 
The HADS is divided into four ranges: the absence of disorders ( 0 to 7$)$, suspected anxious or depressive disorders ( 8 to 10$)$, moderate disorders (11 to 15 ), and severe disorders (16 to 21 ) [20]. A score ranged between 0 and 14 means the absence of anxious depressive disorders and the score ranged between 15 and 42 means the presence of anxious depressive disorders [21]. The independent variables were age, sex, marital status, educational level attained, occupation, level of dependence attained, anxiety, and depression. The dependent variable was the psychological burden.

\section{Statistical analysis}

Statistical analyses were performed using IBM SPSS Statistics version 22.0. Values were reported as proportions and percentages for categorical variables and mean \pm standard deviation for quantitative variables. Stroke survivors and caregivers dyads were dichotomous in two groups based on the burden (ZBI-20), anxiety (HADS A>7), depression (HAD D>7), and anxietydepressive disorders $(\mathrm{HAD}>14)$. Then, a group comparison between demographic factors and the psychological burden was performed using the Mann-Whitney $U$ test for quantitative variables. The exact test of the Fischer was performed for the other variables. The threshold of statistical significance was set at $\mathrm{p}$-value $<0.05$.

\section{Results}

\section{Socio-demographic characteristics}

Overall, the survivors of stroke were younger than the caregivers (mean age: $42.3 \pm 14.39$ years versus $59 \pm 13$ years), with more female than male participants among the stroke survivors and caregivers dyads. The majority of stroke survivors was unemployed and attained a higher educational level. Most of the caregivers were married, first-degree relatives to the stroke survivors; did not receive any training in taking care of stroke survivors, and reported the lack of family support. Severe disability was found among $50.6 \%$ of stroke survivors [Table 1].

\section{Psychological burden's profile of the participants}

Table 2 shows $84.7 \%$ of caregivers with a psychological burden classified as mild to moderate in $64.7 \%$ of cases; moderate to severe burden in $18.8 \%$ of cases; and severe burden in $1.2 \%$ of cases. This psychological burden took more expression of depressive disorders than anxiety disorders among caregivers (Fischer test of 35.3\% versus 32.9). 31\% of survivors of stroke met the diagnosis of depressive disorders (HADS D $>7$ ); $24.7 \%$ belonged to the diagnosis of anxiety disorders 
(HADSA $>7$ ) and $27.1 \%$ met the criteria of mixed type of depression and anxiety (HADS $>14$ ).

\section{Group comparison}

Table 3 revealed that having a burden was significantly associated with the depressive disorder $(\mathrm{p}=$ $<0.001)$, anxiety disorders $(\mathrm{p}=0.0027)$, and mixed type $(\mathrm{p}=0,001)$ in caregivers. The presence of psychological burden was significantly correlated to the severity of the disability. Being a relative to the stroke survivors, attaining a higher educational level, having an occupation, and being a female was not statistically associated with the presence of burden. The Majority of caregivers were first-degree relatives to stroke survivors among which $41.2 \%$ were children and $37.6 \%$ of cases were husband or spouse. $65.9 \%$ of caregivers were taking care for the first time of their relatives, survivors of stroke, and did not receive any formal training in taking care of their family.

\section{Discussion}

This study documents the link between the psychological burden in caregivers and the level of disability in stroke survivors far from the acute phase of the stroke. We observed that nearly nine of ten caregivers and stroke survivors experienced the psychological burden. The results of this study highlight the severe disability in stroke survivors by means of the mRS. Although the prevalence rate of individuals with disabilities was ranged within the average of the WHO [21], this study clearly mirrors the actual conditions of the survivors of stroke in low-income countries characterized by full dependence from their relatives [22, 23].

This study evidenced that caregivers were younger than the survivors of stroke with their firstdegree relatives being concerned. These findings highlight the financial burden associated with taking care of patients with disabilities. The involvement of young people among caregivers in physical rehabilitation programs is associated with low income and poor outcomes among stroke survivors in Africa [24, 25]. Insufficient provision of basic needs of stroke survivors increases the psychological burden reflected by depression and anxiety. Additionally, the results revealed an equal distribution of anxiety in male and female caregivers $[16,20]$.

This study evidences that sixty-five percent of the participants were taking care of their relatives for the first time. The overwhelming among family members leads to the choice of anyone available to become a caregiver, especially the unemployed and the younger [24, 26]. Cultural beliefs to reduce the burden related to the stroke emphasized the avoidance of caregivers of poor taking care history. This behavior is further reinforced by the need for quick recovery from the disability by the relatives with high income [27]. 
Our results revealed that caregivers had more depression than anxiety. The prevalence rate of depression and anxiety varies according to different studies $[28,29]$. Mild depression needs to be assessed in both patients with disability and their caregivers, given the high risk of developing the severe form of depression similar to the worsened health state of stroke survivors. As emphasized by Margaret and colleagues who worked on the prevalence of depression in parents of children with intellectual disabilities in Kenya, over time the parents of the studied population with depression had a high risk of developing the severe form in $79 \%$ of cases $[30,31]$. Numerous studies revealed that anxiety in stroke survivors is associated with poor social support, estimated at up to $10 \%$ by Mpembi and colleagues in survivors of stroke [16], and $24.9 \%$ by Kessler and colleagues in the general population [32].

The study found a link between the presence of burden and depression or anxiety in stroke survivors and caregivers. Preliminary data indicated that the more the burden of supporting their relatives, the greater the expressed psychological distress $[28,30]$. Furthermore, the lack of family support is linked to the increased prevalence of mental disorders in stroke survivors who end to develop vascular depression in nearly $50 \%$ of cases [21]. Our results revealed that as much as one-quarter of study participants had anxiety and depressive disorders. A stroke is followed by long-term consequences including anxiety and depression in stroke survivors and their caregivers. The severe disability was significantly correlated to the presence of burden. In fact, the severe disability requires most of the attention of caregivers including full dependence [26].

\section{Limitations}

Limitations of the study include the convenience sample and the cross-sectional study. Although the stroke survivors are seen far from the acute stroke, the inclusion of stroke survivors with a different period without the study of the relationship between the occurrence of burden and the timing of the stroke is a clear limitation. The ZBI and HAD translated in the local language could limit the collection data of patients with poor educational backgrounds.

\section{Conclusions}

Study findings evidence a positive relationship between severe disability and the occurrence of burden among stroke survivors and their caregivers. Caregivers developed more likely anxiety and depression than stroke survivors. Healthcare providers working with the survivors of stroke should assess for anxiety and depression in caregivers, given that the latter the outcomes of the management of the disability-related to stroke. 


\author{
Abbreviations \\ DRC: Democratic Republic of Congo \\ HADS: Hospital Anxiety and Depression Scale \\ mRS: Rankin's modified score \\ ZBI: Zarit Burden Inventory \\ WHO: World Health Organization
}

\title{
Acknowledgments
}

The authors would like to thank all the stroke survivors and caregivers dyads who accepted to participate in this survey. We would like to acknowledge the research assistants for their passion and dedication during the conduction of this study

\section{Authors' contribution}

G.M.B.K. helped in designing the study, collected data, and analyzed the data in the manuscript. B.M.V. drafted and reviewed the manuscript and was involved in literature searching. M.M.V. and G.M.L. were involved in correcting the collected data. S.M.L, T.M.M.N., M.N.M., and S.M.M.M. were involved in intellectual content and reviewed the manuscript. The authors read, contributed to, and approved the final manuscript.

\section{Funding}

No funding

\section{Ethics approval and consent to participate}

The research protocol received approval by the Ethics Committee of the Public health of the University of Kinshasa. Permission to carry out the study was received from the Executive Director of the rehabilitation center for physical disability in Kinshasa. Participants provided informed consent after being explained the objectives of the study. This study was conducted according to the Declaration of Helsinki.

\section{Competing interests}


The authors declare that they have no competing interests.

\section{Consent for publication}

"Not applicable"

\section{Availability of Data and Materials}

The data used to support the findings of this study are available from the corresponding author upon request.

\section{References}

1. Akosile CO, Okoye EC, Nwankwo MJ, Akosile CO, Mbada CE. Quality of life and its correlates in caregivers of stroke survivors from a Nigerian population. Qual Life Res. 2011;

2. Cossi MJ, Gobron C, Preux PM, Niama D, Chabriat H, Houinato D. Stroke: Prevalence and disability in Cotonou, Benin. Cerebrovasc Dis. 2012;

3. van Heugten CM, Visser-Meily A, Post M, Lindeman E. Care for carers of stroke patients: Evidence-based clinical practice guidelines. J Rehabil Med. 2006;

4. Pandey RN, Halder S, Rath P. Development and validation of "Caregiver Burden ScaleIndian Population.” Int J Prev Med. 2019;

5. Abdollahpour I, Nedjat S, Noroozian M, Golestan B, Majdzadeh R. Development of a caregiver burden questionnaire for the patients with dementia in Iran. Int J Prev Med. 2010;

6. Balogou AAK, Grunitzky EG, Assogba K, Apetse K, Kombate D, Amouzouvi D. Accidents vasculaires cerebraux chez le sujet jeune ( 15 a 45 ans) dans le service de neurologie du CHU campus de Lome. African J Neurol Sci. 2008;

7. Anderson CS, Linto J, Stewart-Wynne EG. A population-based assessment of the impact and burden of caregiving for long-term stroke survivors. Stroke. 1995;

8. Bhattacharjee M, Vairale J, Gawali K, Dalal PM. Factors affecting burden on caregivers of stroke survivors: Population-based study in Mumbai (India). Ann Indian Acad Neurol. 2012;

9. Glymour MM, Weuve J, Fay ME, Glass T, Berkman LF. Social ties and cognitive recovery after stroke: Does social integration promote cognitive resilience? Neuroepidemiology. 2008; 
10. Dennis M, O'Rourke S, Lewis S, Sharpe M, Warlow C. A quantitative study of the emotional outcome of people caring for stroke survivors. Stroke. 1998;

11. Tessier A, Finch L, Daskalopoulou SS, Mayo NE. Validation of the Charlson Comorbidity Index for Predicting Functional Outcome of Stroke. Arch Phys Med Rehabil. 2008;

12. Has. «Ensemble, améliorons les pratiques de prise en charge de l'Accident Vasculaire Cérébral ». Program AVC 2009-2014. 2010;

13. Pucciarelli G, Ausili D, Galbussera AA, Rebora P, Savini S, Simeone S, et al. Quality of life, anxiety, depression and burden among stroke caregivers: A longitudinal, observational multicentre study. J Adv Nurs. 2018;

14. Clarke DJ, Forster A. Improving post-stroke recovery: The role of the multidisciplinary health care team. Journal of Multidisciplinary Healthcare. 2015.

15. Zigmond AS, Snaith RP. The Hospital Anxiety and Depression Scale. Acta Psychiatr Scand. 1983

16. Mpembi MN, Miezi SM ma, Peeters A, de Partz M-P, Henrard S, Massamba VK, et al. Sociodemographic profile and social support for post-stroke depression in Kinshasa: A rehabilitation based cross-sectional study. Open J Epidemiol. 2013;

17. Boutoleau-Bretonnière $\mathrm{C}$, Vercelletto $\mathrm{M}$, Volteau $\mathrm{C}$, Renou $\mathrm{P}$, Lamy E. Zarit burden inventory and activities of daily living in the behavioral variant of frontotemporal dementia. Dement Geriatr Cogn Disord. 2008;

18. Bjelland I, Dahl AA, Haug TT, Neckelmann D. The validity of the Hospital Anxiety and Depression Scale: An updated literature review. J Psychosom Res. 2002;

19. Denno MS, Gillard PJ, Graham GD, Dibonaventura MD, Goren A, Varon SF, et al. Anxiety and depression associated with caregiver burden in caregivers of stroke survivors with spasticity. Arch Phys Med Rehabil. 2013;

20. Balhara YS, Mathur S, Sharma S, Verma R. A study of predictors of anxiety and depression among stroke patient-caregivers. J Midlife Health. 2012;

21. Shahly V, Chatterji S, Gruber MJ, Al-Hamzawi A, Alonso J, Andrade LH, et al. Crossnational differences in the prevalence and correlates of burden among older family caregivers 
in the World Health Organization World Mental Health (WMH) Surveys. Psychological Medicine. 2013.

22. Carmo JF do, Morelato RL, Pinto HP, Oliveira ERA de. Disability after stroke: a systematic review. Fisioter em Mov. 2015;

23. Mutume Vivalya B, Manzekele G, Kitoko B, Nzanzu AK, Vagheni MM, Masuka RK, et al. Affective and Psychotic Disorders in War-Torn Eastern Part of the Democratic Republic of the Congo: A Cross-Sectional Study. 2020;

24. Badaru UM, Ogwumike OO, Adeniyi AF, Nelson EE. Determinants of caregiving burden and quality of life of informal caregivers of African stroke survivors: Literature review. Int $\mathbf{J}$ Disabil Hum Dev. 2017;

25. Abzhandadze T, Forsberg-Wärleby G, Holmegaard L, Redfors P, Jern C, Blomstrand C, et al. Life satisfaction in spouses of stroke survivors and control subjects: A 7-year follow-up of participants in the sahlgrenska academy study on ischaemic stroke. J Rehabil Med. 2017;

26. Ostwald SK, Godwin KM, Cron SG. Predictors of life satisfaction in stroke survivors and spousal caregivers after inpatient rehabilitation. Rehabil Nurs. 2009;

27. Gbiri CA, Olawale OA, Isaac SO. Stroke management: Informal caregivers' burdens and strians of caring for stroke survivors. Ann Phys Rehabil Med. 2015;

28. McLennon SM, Bakas T, Jessup NM, Habermann B, Weaver MT. Task difficulty and life changes among stroke family caregivers: Relationship to depressive symptoms. Arch Phys Med Rehabil. 2014;

29. Tang WK, Lau CG, Mok V, Ungvari GS, Wong KS. Burden of chinese stroke family caregivers: The Hong Kong experience. Arch Phys Med Rehabil. 2011;

30. Mbugua MN, Kuria MW, Ndetei DM. The Prevalence of Depression among Family Caregivers of Children with Intellectual Disability in a Rural Setting in Kenya. Int J Family Med. 2011;

31. Ain QU, Dar NZ, Ahmad A, Munzar S, Yousafzai AW. Caregiver stress in stroke survivor: data from a tertiary care hospital -a cross sectional survey. BMC Psychol. 2014;

32. Koleck M, Gana K, Lucot C, Darrigrand B, Mazaux JM, Glize B. Quality of life in aphasic 
patients 1 year after a first stroke. Qual Life Res. 2017; 


\section{Supplementary Files}

This is a list of supplementary files associated with this preprint. Click to download.

- Table2.docx

- Table3.docx

- Table1.docx 